\title{
O "ficar" na adolescência e paradigmas de relacionamento amoroso da contemporaneidade
}

\author{
José Sterza Justo ${ }^{\star}$
}

\begin{abstract}
Resumo
O ficar é um relacionamento afetivo bastante popular entre os adolescentes e caracteriza-se por ser breve, passageiro, imediatista, volátil e descompromissado. Análises comparativas demonstram que o ficar obedece à mesma lógica que rege outros relacionamentos. Seu caráter provisório e efêmero está presente, por exemplo, na abreviação dos vínculos empregatícios e na rarefação de relacionamentos outrora sólidos e duradouros tais como os de vizinhança e familiais. Vive-se hoje uma condição de aceleração do tempo, alargamento de espaço e movimentação humana sem precedente, impeditiva de vinculações psicossociais estáveis e prolongadas em todos os planos da vida: do amor ao trabalho.
\end{abstract}

Palavras-chave: Ficar; adolescência. Relacionamento. Afetividade. Contemporaneidade.

\section{"To stay with" ("ficar") among teenagers and paradigms of love ties nowadays}

\begin{abstract}
"To stay with" someone ("ficar") is a quite popular affective type of relationship among teenagers and it is characterized by being brief, fleeting, immediate, fickle and without commitment. Comparative analyses show that "to stay with"("ficar") follows the same logic which governs fixed ties in other types of relationship. Its particularly provisory and fleeting feature is found, for example, in professional ties in short-term employment, in relationships which were once long-lasting and steady, such as that among neighbours, not to mention family ties. Nowadays, one lives an unprecedented process of time acceleration, space expansion and human rush, which makes it impossible to establish stable and lasting psychosocial ties at all levels of life: from love to work.

Keywords: To stay with. Teenagers. Relationships. Affection; Contemporary world.

* Psicólogo, Mestre em Psicologia Educacional e Doutor em Psicologia Social pela Pontifícia Universidade Católica de São Paulo. Professor do Departamento de Psicologia Evolutiva, Social e Escolar (graduação e pós-graduação em Psicologia) da Faculdade de Ciências e Letras. Universidade Estadual Paulista (Unesp) - Campus de Assis, SP. Endereço: Avenida D. Antonio, 2100. CEP 19806900 Assis, SP. E-mail: justo@assis.unesp.br
\end{abstract}




\section{INTRODUÇão}

Mais do que outras idades da vida, a adolescência passou a ser reconhecida e representada como um período de forte presença das chamadas "influências sociais" no funcionamento psicológico e na constituição do sujeito. As figurações sobre o adolescente e a adolescência aludem, freqüentemente, e não é de hoje, a conflitos com o mundo, com os pais e com os adultos. Imagens de rebeldia, inconformismo, idealismo, vanguardismo, mudança, revolução e tantas outras alusivas a confrontos e ao espírito de transformação do mundo estiveram bastante associadas a esse período da vida. Aliás, tais imagens foram exaustivamente utilizadas para a instituição dessa fase da vida como um período singular, diferenciado dos demais e altamente valorizado.

A adolescência, sobretudo no século XX, foi elevada como representante e expressão máxima da juventude, da potência, da beleza, da liberdade, do gozo, do espírito crítico e contestador, do progresso, da disposição para a mudança e de tantos outros atributos que a tornaram uma fase bastante prestigiada e cobiçada. É verdade, também, que essa fase foi vista como momento de vivência das grandes crises (afetivas, emocionais, de identidade, de valores etc.) e sofrimentos. Porém, tais crises foram consideradas positivas e construtivas já que o saldo final sempre representava um ganho e melhoria do sujeito. Aliás, a própria idéia de crise alude a movimento, mudanças, ruptura e desestruturação que, embora possam estar associadas a sofrimentos, trazem como significação básica a potencialização da vida e a dinamização do sujeito e do seu mundo. A chamada "crise da adolescência" sempre foi referida com signos situados em corredores semânticos meliorativos diferentemente de "crises" de outras idades semiotizadas em corredores semânticos pejorativos, como é o caso da aludida "crise do envelhecimento" ou da "aposentadoria", inevitavelmente associadas a imagens de degradação, desvitalização, enfraquecimento etc..

Tanto a ciência como o senso comum acabaram por eleger a adolescência como a fase das grandes transformações biopsicológicas e sociais responsáveis pelo último grande impulso do processo do desenvolvimento humano e como o período das realizações fundamentais e do "acabamento" final do sujeito, Teorias psicológicas importantes, como a psicanálise e a epistemologia genética, encerram a periodização do desenvolvimento na adolescência, tomada como a fase de coroamento das conquistas, transformações e realizações anteriores. De maneira geral, as teorias psicológicas do desenvolvimento enfatizam a presença das relações sociais do adolescente como elemento disparador dos fenômenos dessa fase. A adolescência é considerada a fase de passagem de um círculo social restrito e primário - a família - para um universo social muito mais amplo e secundário - o mundo todo. A entrada no "mundo", a conquista da autonomia, a "independência" volitiva e intelectual, a superação da tutela econômica e jurídica, são alguns dos reconhecimentos da prontidão social do adolescente. O senso comum também 
reconhece a adolescência como o momento de ingresso no mundo adulto e na sociedade mais ampla.

Tal ingresso no mundo adulto é repleto de rituais que consagram essa transição. O menino é visto como aquele que está se tornando, definitivamente, "homem": a barba, a sexualidade, a inserção no trabalho, a saída de casa, o serviço militar, são alguns dos tantos signos desses rituais de passagem. A menina, além de passar por imagens similares àquelas que denotam a transformação do menino em "homem", como o reconhecimento de sua sexualidade ou as saídas mais freqüentes e duradouras de casa para estudar, trabalhar ou para o lazer, vive sua transformação em "mulher" em rituais específicos como a tradicional cerimônia de debutante, na classe média. O senso comum, especialmente nas classes populares, possui uma infinidade de códigos de reconhecimento do adolescente como um quase-adulto, incluindo até mesmo seu reconhecimento como alguém hostil e temido.

São notáveis em todas essas representações da adolescência, pela ciência ou pelo senso comum, referências às mudanças, principalmente no campo social. Em ambos os casos é marcante a retratação do adolescente como alguém bastante suscetível a influências sociais e participante da vida pública aqui entendida simplesmente como as relações sociais travadas no espaço público, o que inclui todo o espaço da vida noturna, por exemplo.

Essa relação íntima da adolescência com o espaço social talvez expresse mesmo um momento privilegiado para a compreensão das injunções sociais no sujeito. Talvez, mais do que em outras idades, a adolescência expresse as tendências e contradições de um tempo e lugar ou da história, da sociedade e da cultura, devido à sua maior exposição e sensibilidade às questões e idiossincrasias da contemporaneidade. Também é provável que aconteça essa maior exposição ao mundo porque não há uma blindagem no plano micropolítico, como ocorre com a criança, quando os pais conseguem amortecer o impacto dos problemas sociais. Além disso, o adolescente não possui, como um adulto ou um idoso, um lastro de defesas egóicas capaz de aliviar o impacto na subjetividade de mudanças no cenário socioeconômico e cultural.

Por isso mesmo os fenômenos típicos da adolescência são expressões privilegiadas das tendências da contemporaneidade que ressoam com maior rapidez e transparência. Não é à toa que questões como a violência, o uso de drogas, o desemprego e a inserção no mercado de trabalho tornam-se mais agudas ou se expressam com maior radicalidade nessa fase.

É com o propósito de compreender as vicissitudes da sociedade contemporânea que nos propomos a desenvolver aqui algumas reflexões sobre os relacionamentos afetivos e amorosos na adolescência.

\section{AdolescênCIA, CULTURA BRASILEIRA E CONTEMPORANEIDADE}


A valorização da adolescência, amplamente expressa na cultura ocidental, no século XX, recebeu um reforço adicional na cultura brasileira bastante afeita à novidade, inovação, mudança e outros atributos infundidos a esse período da vida. Como é sobejamente apregoado, a cultura brasileira, diferentemente da Européia ou da dos países Andinos, por exemplo, não se baseia em tradições milenares, no cultivo da memória social, na evocação de acontecimentos fundadores da nação, em celebrações de seus feitos fundamentais, em símbolos expressivos de uma identidade nacional e assim por diante.

Tal como afirma Calligaris (1992), a formação da cultura brasileira, fundada na ruptura do imigrante com suas referências anteriores - a pátria abandonada - alimenta-se do corte ou negação do passado e da extrema valorização do novo, do presente e do futuro. Segundo o autor, a própria denominação de muitas cidades denota esse ideário de ruptura e refundação da vida no eldorado brasileiro: "Nova" Friburgo, "Nova" Odessa, "Nova" Hamburgo e assim por diante.

Essa necessidade de renomear com o prefixo "novo" antigas e tradicionais cidades européias indica a intenção de recriar o antigo completamente, dar-lhe uma feição totalmente inovadora, com toda certeza retirando-lhe tudo que pudesse enfeiá-lo ou significar algum sofrimento.

A cultura brasileira nasce de um encontro ou de um confronto, como se queira, de três raças - o branco europeu, o negro africano e o vermelho indígena como enfatizam Azevedo (1963) e Freyre (1936). Apesar da desigualdade estabelecida entre elas pela forte dominação do europeu, subsistiu a miscigenação como acontecimento inevitável que deixou traços marcantes da cultura brasileira, entre eles, a abertura para o novo, o diferente, o estrangeiro, mesmo dentro de estruturas familiais patriarcais rígidas e autoritárias. A sexualidade é destacada por esses autores como algo que exerce um papel fundamental na gênese e na constituição da brasilidade. Azevedo chega a tomar o romance Iracema de José de Alencar como demonstração simbólica do "amor que as filhas do país tinham ao aventureiro branco" e como uma metáfora das "núpcias da terra virgem" com o "colono civilizador" (AZEVEDO, 1963, p. 69). Freyre (2000), centrando-se nas transformações geradas pela instauração do regime republicano, defronta-se exatamente com a questão de entender de que forma se manteve a organicidade social e a unidade nacional com a ebulição dos interesses progressistas que mudavam, inclusive, a orientação da bússola brasileira da Europa para os EUA. As respostas, nada simples, passam pela capacidade de permanência de certas estruturas por meio de ritos e a inserção de novas relações econômicas e sociais com a vinda de imigrantes.

Com todos os percalços, ambigüidades e contradições a cultura brasileira soube conviver, articular e sintetizar, num tempo e modo próprios, o espírito conservador com o progressista, o culto às tradições com a valorização do novo e do estrangeiro. O slogan "Ordem e Progresso", que não está por acaso no centro da bandeira nacional, expressa exatamente o ideal modernizador assentado na disciplina rígida e no desenvolvimento tecnológico-industrial. 
Mas não foram tão-somente os ideários de renovação, transformação e ruptura com arcaísmos que conseguiram vicejar no Brasil sob bandeiras modernistas, superando resistências ou compondo com elas. Os mais recentes valores, relações sociais e subjetivações emergentes na contemporaneidade, chamados por alguns de pós-modernidade (SANTAELLA, 1996; HARVEY, 1998) também encontram o solo fecundo na cultura brasileira. Talvez como nenhuma outra, nossa cultura encarna os valores essenciais da contemporaneidade. A idéia de miscigenação, de convivência com as diferenças e com as impurezas, tão circulante no pensamento pós-moderno, em oposição ao ideário de pureza da modernidade, está muito e profundamente presente na mentalidade do brasileiro.

Progresso, dinamismo, mestiçagem, sensualidade, afetividade, prazer, errância e migração, são marcas da contemporaneidade fortemente impressas na cultura brasileira (AZEVEDO, 1963; FREYRE, 2000). Trata-se de um povo com raízes e vinculações fortemente marcadas pelo espírito de aventura e pelo nomadismo, herança dos portugueses (AZEVEDO, 1963; MAFFESOLI, 2001), possibilitando mobilidades psicossociais e geográficas. A migração ou a condição de transeunte - típica da supermodernidade - segundo Augé (1994), é perfeitamente assimilada pelo brasileiro, capaz de deslocar-se para lugares longínquos em busca da felicidade, tal como fizeram seus antepassados. As migrações internas entre cidades, regiões do país e as emigrações para o exterior, tão presentes no cenário brasileiro, nesse particular herdeiro absoluto das tradições dos viajantes portugueses, expressam a maleabilidade das vinculações socio-afetivas e geográficas desse povo. Poderíamos afirmar que o brasileiro não desenvolve apegos exagerados, capazes de aprisioná-lo em lugares identitários fixos: a cidade, a região ou o próprio país. Aliás, é conhecido o distanciamento que mantém em relação às referências identitárias nacionais: a bandeira, o hino e os demais símbolos da brasilidade são até mesmo ridicularizados.

Isso tudo faz do brasileiro um povo extremamente aberto às influências externas e ao mundo: é capaz de se globalizar sem maiores dificuldades. Não erige fronteiras rígidas (políticas, econômicas, geográficas, sociais, sexuais) e se mostra disponível tanto para adentrar o universo alheio como para receber o estrangeiro.

Trata-se de um país e de uma cultura que enaltece o novo, que possui o desprendimento como norma, que é desregulamentado, como bem mostra o jeitinho brasileiro flexível e com "jogo de cintura", venera o estrangeiro, o desconhecido, o diferente e assim por diante.

Pois bem, o culto ao novo, à renovação e a rupturas com estruturas antigas, marcas registradas da modernidade (BERMAN, 1986), acaba valorizando, entre outras coisas, o jovem e a adolescência e isso, evidentemente, como característica de um tempo, não é exclusivo da brasilidade.

Entre nós, observa-se com facilidade a supervalorização dos jovens e a depreciação exagerada dos idosos. No trabalho, na escola, na saúde, no lazer, nos meios de comunicação e em tantos outros lugares é notável a presença da jovialidade. Uma simples ronda por uma cidade revelará a presença maciça dos jovens 
nos espaços públicos. A cidade é dos jovens, diferentemente do acontece em muitos outros países. O trabalho, a televisão, o shopping center - Meca da sociedade atual - são maciçamente ocupados por jovens ou dirigidos para eles. São os principais alvos do consumo e da publicidade, num mundo em que o consumo é centro organizador da vida e da sociedade, do espaço urbano, da cidadania, do sujeito (somos o que consumimos), das identidades (espelhamo-nos nas marcas e grifes) e da produção e projeção da imagem do sujeito, de seu reconhecimento, de sua auto-estima e de seu poder.

A cultura da mobilidade, da flexibilidade, da efemeridade e da provisoriedade também elege o adolescente como modelo. A ele são imputadas tais qualidades e sobre ele é que, principalmente, vão-se realizar esses desígnios da contemporaneidade e as subjetivações pertinentes. O adolescente é o protótipo do sujeito errante, sem raízes ou em processo de derenraizamento, desterritorializado, plástico, flexível, consumista (adolescência e shopping se confundem), narcisista etc.. Num país de enorme extensão territorial como o nosso, a visada de um amplo horizonte conjugada com condições econômicas instáveis, impõe à população movimentações constantes, criando situações diversas de migração (campo/cidade; norte e nordeste/ sul e sudeste, pequenas cidades/grandes metrópoles) ou de deslocamentos temporários para estudo ou trabalho. Muitas vezes tais exigências de deslocamento fazem os mais arrojados se deslocarem para outros países e continentes em busca de trabalho e de melhores condições de vida.

Esse cenário de instabilidade incide de forma mais brutal sobre o adolescente impelido a rastrear melhores possibilidades e rumos para sua vida. A busca por qualificação profissional através de cursos superiores, no caso da classe média, e a busca de melhores oportunidades de trabalho, no caso dos jovens pobres, torna a adolescência brasileira bastante propensa à errância e à desterritorialização. Tal errância ou desterritorialização implica a disposição para promover e vivenciar situações de "desencaixes" e "re-encaixes" (GIDDENS, 1991), por meio de mudanças nos lugares de habitação, significando isso toda uma reconstrução das relações sociais internalizadas nos lugares de origem.

Embora a condição de errante ou migrante não seja exclusiva dos adolescentes, é sobre eles que ela se faz mais imperiosa. Precisam "sair de casa" para estudar, trabalhar ou viver conjugalmente com outra pessoa, muitas vezes, tendo que migrar para regiões distantes ou permanecerem nessa condição de "caixeirosviajantes", em constante trânsito, em função das exigências do trabalho. Essa condição de movimentação, típica da contemporaneidade e potencializada pelas condições socioeconômicas vigentes na sociedade brasileira, torna o adolescente um verdadeiro itinerante. Além disso, essa sua função social de portador dos germes das mudanças que processam os saltos de diferenciação de uma geração para outra fazem dele o porta-voz da intensificação, cada vez maior, das tendências que se despontam na contemporaneidade. Assim é que, além de itinerante, o adolescente torna-se expressão do aumento do ritmo de vida (aceleração do tempo no cotidiano), da plasticidade e multiplicidade, constituindo-se como um sujeito móvel em todos os sentidos: não apenas possui facilidade para se deslocar no espaço geográ- 
fico, como também o faz no plano social e psicológico. A itinerância exige plasticidade afetiva, capacidade para estabelecimento de vinculações transitórias e abreviadas, para adaptações de hábitos, rotinas, para renovações de idéias e valores, enfim, exige uma maleabilidade em todos os planos da vida.

A volatilidade do sujeito expandido para além das fronteiras locais de seus assentamentos primevos, à feição do que exige a globalização, desestimula qualquer processo de produção de identidades ou de estabilização. Tal como se observa na rarefação da identidade nacional e na extrema abertura da cultura brasileira para o exterior e o estrangeiro, o sujeito da atualidade não tende para uma estruturação unitária e contínua. É descentrado, múltiplo, maleável, desenraizado ou "rizomático", dispersivo mais do que concentrador, ou seja, estrutura-se "em rede" e não mais em torno de um "centro", de um "eixo" ou de um "núcleo" tal como era apresentado nas teorias psicológicas tradicionais.

Além de ser "uma metamorfose ambulante", o adolescente encarna ainda o espírito de renovação e progresso, bastante presente na cultura brasileira, e o signo da "virulência afetiva" não apenas reconhecida como marca brasileira (AZEVEDO, 1963), mas de toda América Latina.

A sanha de construção e reconstrução que se remonta às visadas dos primeiros colonizadores ainda persiste na nossa cultura de forma intensa. Subisiste a crença de que ainda há muito que se fazer, descobrir, transformar e construir nesse país. Regiões mais longínquas das mais urbanizadas, como a Amazônia, funcionam como bastiões de reserva das miragens de conquista e progresso. Tais sonhos e miragens também são depositados, sobretudo, sobre os mais jovens, em especial, sobre os adolescentes. A eles é atribuída a função de desbravar territórios ainda inexplorados e atualizar as estratégias de desenvolvimento da sociedade e de "conquista do paraíso", sonho esse sempre postergado de geração para geração, tornando o brasileiro um esperançoso e eterno sonhador.

Há de se considerar, entretanto, que o otimismo e a crença num futuro melhor já foram mais arraigados na mentalidade dos brasileiros. As representações do país como o país do futuro, remontadas às primeiras miragens dos imigrantes, já cederam em parte, dando lugar a sentimentos mais pessimistas ou menos confiantes e idolatrantes. Aliás, a compressão do tempo, assinalada por muitos autores como uma das marcas da contemporaneidade (BAUMAN, 1998), esvaece a noção de passado, presente e futuro, situando o sujeito em um tempo único na qual o imediatismo prevalece como lógica de satisfação dos desejos e necessidades.

Conforme enfatiza Bauman (1998), vivemos hoje o chamado "tempo real" em que as distâncias se encurtam de tal forma a tornar tudo imediatamente presente. Vivemos a era da "instantaneidade" em que não é mais preciso aguardar, esperar ou retardar a satisfação de um desejo, um gesto, uma palavra, e assim por diante. Tudo funciona 24 horas e há ainda a pronta entrega, desde pizzas até operações bancárias. O celular, por sua vez, faculta a comunicação a qualquer hora e lugar. Não sendo mais necessário qualquer postergação mínima ou adiamento, vive-se o sonho da pronta e plena satisfação, afastando-se o fantasma da frustração. Dentro do referencial psicanalítico, entenderíamos essa condição como de 
soberania do processo primário sobre o secundário, tal como funciona o bebê ao exigir o pronto atendimento e a satisfação de suas necessidades e desejos.

Dentro dessa lógica, o futuro não está por vir, mas já chegou, podendo até ser adiantado como acontece com a antecipação do consumo por meio da compra mediante o sistema de crediários ou de outras formas de endividamento.

Enquanto subjetivador por excelência da lógica da instantaneidade, o adolescente se coloca nem tanto mais como o futuro ou promessa da realização dos sonhos das gerações anteriores, mas como aquele que está à frente de seu próprio tempo, portanto, já consumando o próprio futuro. Aliás, o sonho enquanto uma visada longínqua já não tem lugar no mundo da instantaneidade. No máximo, pode aludir a algo que esteja ao alcance e que possa ser conquistado rapidamente.

$\mathrm{O}$ adolescente encontra-se premido por um tempo que avança rapidamente tendo que elaborar e movimentar-se na profusão de acontecimentos que se desencadeiam à sua volta. É sobre ele que se realiza mais extensiva e radicalmente a ruptura das fronteiras do tempo tornando-o um sujeito instantâneo, pronto para responder a todas as demandas e ondas que se formam ao seu redor. Não pode adiar ou remeter para um "futuro" algumas realizações e necessidades. O mundo do consumo não comporta adiamentos, apegos, estabilizações, recusas, renúncias, parcimônia, paciência e tolerância. Necessita, isso sim, de um sujeito ativo, questionador, impaciente, instável, pronto para renovar seus desejos, impulsivo, intolerante, inconformado, incapaz de renunciar e conviver com frustrações. $\mathrm{O}$ adolescente representa a metamorfose ambulante, o ritmo frenético, a velocidade, a competitividade, o vigor produtivo e consumista

É também sobre ele que recai a função de subjetivação de outra grande marca da contemporaneidade: a religação do sujeito nas redes de informação e de produção de realidade virtual. São principalmente os adolescentes que se tornaram alvo da internet e da informática. Não é à toa, inclusive, que os jovens têm sido apresentados como empreendedores bem-sucedidos nesse mercado. São vários os casos amplamente difundidos pela mídia de adolescentes que fizeram grandes descobertas nesse campo e criaram alguns produtos que os tornaram milionários rapidamente. Até os comerciais de televisão usam a imagem da criança que domina facilmente essa tecnologia e a ensina para seus pais. É enorme a influência da informática, da internet e dos demais meios de virtualização da realidade na socialidade dos adolescentes.

A cultura do descarte é outra marca da contemporaneidade que enaltece a adolescência e vitimiza especialmente os idosos. O consumismo depende, evidentemente, do descarte de objetos de consumo com a conseqüente renovação da demanda. É também evidente que a propensão para o descarte depende de uma disposição psicológica na relação com objetos, de tal forma que o abandono e o descarte sejam premiados com o prazer e as práticas de retenção e conservação sejam castigadas com desprazer. Tal disposição psicológica para o descarte estrutura-se no plano emocional afetivo orientador das relações do sujeito com as coisas do seu mundo, incluindo aí, principalmente, as outras pessoas como os princi- 
pais objetos de suas relações e visadas do seu desejo. Portanto, as atitudes para com as "mercadorias" propriamente ditas inevitavelmente estarão relacionadas com a orientação geral para o mundo e com o tipo de vinculações estabelecidas pelo sujeito com esse mundo. Portanto, a descartabilidade não se realiza apenas com os chamados "objetos de consumo" mas com todos os objetos. Na verdade, ela designa um modo de relacionamento do sujeito com seu mundo instaurado pela efemeridade e o imediatismo.

A cultura do descartável, assentada no consumismo, invade as subjetividades solapando as clássicas figuras da identidade que destacam a estabilidade e a solidez. Porém, como lembra Rolnik (1997), a abertura para o novo, capturada pelo mercado, "[...] nada tem a ver com flexibilidade para navegar ao vento dos acontecimentos - transformações das cartografias de forças que esvaziam de sentido as figuras vigentes lançam as subjetividades no estranho e forçam-nas a reconfigurar-se (ROLNIK, 1997, p. 20-21). Criticando o identitarismo fortemente presente nas concepções de sujeito, ela alerta para o fato de que a globalização ao pulverizar as "identidades", minando as fronteiras que a cercavam, acaba apenas substituindo as identidades "locais" pelas "globais flexíveis" produzindo verdadeiros kits-padrão de identidade, disponíveis no mercado para amplo consumo e renováveis a cada onda de moda. Segundo a própria autora, o adolescente hoje vive exatamente a condição do sujeito contemporâneo que delineamos em outro lugar:

Sem dúvida, um mundo que se apresenta móvel, caótico, fragmentado, inflacionado de signos, informação e linguagens, um mundo em constante movimento, produção e consumo que nada acaba ou completa, um mundo que interconecta os seus habitantes, deslocando-os ou inserindo-os em redes de comunicação, que os introduz em todo tipo de sistema Online, um mundo assim constituído não pode ser o lugar de personagens fixas, cristalizadas, unidirecionais nas ações, pensamentos, afetos, sentimentos e formas de expressão e comunicação.Mais do que um sujeito sedentário e sedimentário capaz de acumular, fixar, reproduzir, unificar, universalizar, o mundo contemporâneo solicita um sujeito capaz de multiplicar-se, fracionar-se, viver nomadamente no plano intelectual, afetivo e social, um sujeito que não pare, mas que continue deslizando constantemente por espaços e tempo indefinidos (JUSTO, 2001, p. 73).

\section{ADOLESCÊNCIA CONTEMPORÂNEA E RELACIONAMENTOS AFETIVOS}

O desdobramento das condições de vida criadas na contemporaneidade e as subjetividades aí produzidas são bastante reconhecíveis e notáveis no plano específico dos relacionamentos amorosos. Há algum tempo vem-se observando mudanças na organização da família devido a transformações nos vínculos amorosos e nos relacionamentos que davam suporte à família nuclear tradicional. Dentre as várias razões relacionadas com as modificações na composição do núcleo familial, destacaremos exatamente a força de dispersão, de instabilidade, de 
desterritorialização e de desenraizamento, produtoras de relacionamentos mais abreviados e instantâneos incompatíveis com a estrutura familiar tradicional calcada na exigência de um amor e aliança conjugal eternos.

$\mathrm{Na}$ lógica de compressão de tempo e espaço da contemporaneidade, ou seja, com a aceleração do tempo e a derrubada das fronteiras geográficas e psicossociais, as relações passam a ser mais fluidas, breves, instantâneas, diversificadas e instáveis. Como assinala Giddens (1991), está-se tornando extemporâneo o amor romântico fincado na promessa de amor eterno, na indissolubilidade do casamento, na dedicação total ao parceiro e na predisposição ao sacrifício para consumar o projeto do amor abnegado e indemolível. Em seu lugar surge, ainda segundo o mesmo autor, uma forma de amor e relacionamento amoroso mais plástica: o amor confluente e o relacionamento puro. Neles o afeto e o relacionamento são contingentes e baseados numa negociação de correspondência dentro de uma relação horizontalizada entre homem e mulher e inspirada em valores de igualdade entre as partes. $\mathrm{O}$ amor confluente, diferentemente do abnegado amor romântico, dura enquanto durar a co-satisfação entre os parceiros.

Bauman (1998), assinala outro aspecto dos relacionamentos afetivos da contemporaneidade, assentado na sexualidade. Segundo ele, enquanto antes a sexualidade era colocada a serviço de um projeto de vida ou de um relacionamento, ou seja, orientava-se para a consecução de outros objetivos além do próprio prazer sexual, hoje está desconectada de outras buscas, cumprindo uma finalidade puramente hedonista. A sexualidade assim modelada seria suporte do sujeito "colecionador de sensações", que vive a instantaneidade e o imediatismo, sujeito esse que se constitui basicamente como um consumidor inveterado. Além disso, o isolacionismo e o individualismo da contemporaneidade têm transformado em algo perigoso as aproximações mais íntimas entre as pessoas. Por isso mesmo, a família estaria sendo insistentemente apresentada como um lugar hostil e de perigo para a criança e a mulher, por exemplo, assim como qualquer situação de aproximação ou tentativa de contato entre homem e mulher estaria impregnada do temor paranóico de assédio sexual.

Trata-se, portanto, de um mundo que não favorece a aproximação entre as pessoas, a criação de vínculos duradouros, a associatividade e a grupalização. Nesse cenário, o adolescente se vê impelido a instituir o modo típico de relacionamento desse tempo: relações abreviadas, voltadas para a satisfação de necessidades e desejos imediatos, sem compromissos que ultrapassem o momento da relação. Usando uma expressão radical diríamos que os relacionamentos atuais são instantâneos, ou seja, possuem a exata duração da confluência de demandas efêmeras já que se renovam continuamente e se multiplicam. Não há lugar para relacionamentos duradouros articulados a um projeto futuro, capazes de catalisar demandas diversas e estabilizar relações, especialmente aquelas que circunscrevem pares, casais, pequenos agrupamentos e espaços afetivos locais. 
Em outro lugar já argumentamos que a substituição dos espaços fechados pelos espaços abertos na sociedade contemporânea tende a produzir relações afetivas mais expansivas, temporárias e diversificadas.

Cabe notar que também, e principalmente, a subjetividade
humana é atravessada pelas exigências de movimentação e
ruptura com espaços delimitados e estáveis. As fronteiras
afetivas estão sendo sacolejadas para dar lugar a vínculos
mais fluidos, dispersivos e móveis, ou seja, os afetos estão
sendo também globalizados. Não é à toa que o “ficar" desponta
como a mais nova forma de relacionamento amoroso entre os
adolescentes. (JUSTO, 1997, p. 91).

Dentre os vários tipos de relacionamento afetivo o 'ficar', sem dúvida, é o mais expressivo da cultura adolescente na atualidade. A expressão é bastante utilizada e já ganhou notoriedade. Embora designe um tipo de relacionamento também presente em outras faixas etárias, consagrou-se como um relacionamento próprio dos jovens.

Embora a palavra "ficar" tenha o sentido genérico de parada e permanência, sugerindo uma certa fixação em algum lugar, seu uso pelos adolescentes, ao contrário, designa um relacionamento episódico e ocasional, na maioria das vezes com a duração de apenas algumas horas ao longo de uma noitada de festa e diversão. A prática mais comum envolve beijos, abraços e carinhos. Outra característica importante é que o "ficar" não implica compromissos futuros e é visto como um relacionamento passageiro, fortuito, superficial, sem maiores conseqüências ou envolvimentos profundos.

É um relacionamento bastante popular entre os adolescentes. A maioria o conhece ou já teve alguma experiência. Em pesquisa realizada na cidade de Assis em São Paulo, envolvendo 264 adolescentes - 162 do sexo feminino e 102 do sexo masculino, na faixa etária de 13 a 16 - constatou-se que o "ficar", seguido bem de perto pelo "namorar" foram, de longe, os mais citados como relacionamentos amorosos conhecidos pelos sujeitos (MARIANO, 2001, p. 72, 74). A pesquisa citou como principais diferenças entre esses relacionamentos a duração e o grau de comprometimento ou implicação. Caracterizou o "ficar" como um relacionamento ou uma aproximação despertada por uma atração ou interesse, normalmente num local de encontro de jovens na noite, que acaba resultando em contato físico (carícias, beijos e, eventualmente, relações sexuais) e que dura enquanto durar aquele encontro.

A partir das falas dos sujeitos, a autora da pesquisa sintetiza o "ficar" da seguinte maneira: "predomina no 'ficar' a sensorialidade, a brevidade do contato, a ausência de exclusividade e de compromisso, a descartabilidade do outro e a não-obrigatoriedade da presença de sentimento" (MARIANO, 2001, p. 79).

Embora alguns sujeitos dessa pesquisa tenham se referido ao ficar como um primeiro contato - um primeiro encontro que pode se transformar em namoro - e, apesar de alguns pesquisadores (WEINGARTNER, 1995) considerarem o 
"ficar" como uma experiência preliminar ou um contato exploratório com vistas a um melhor conhecimento do outro, entendemos que subsiste nesse relacionamento a busca mesmo de um relacionamento instantâneo e provisório, à feição do que solicita a sociedade contemporânea.

Entretanto, um dado chamou bastante a atenção nessa pesquisa. O "ficar" não foi citado majoritariamente como o tipo de relacionamento preferido. A preferência maior recaiu sobre o "namoro". A diferença foi bastante significativa: aproximadamente $26 \%$ dos meninos e $9 \%$ das meninas declararam preferir o "ficar", enquanto $41 \%$ dos meninos e $72 \%$ das meninas declararam preferir o "namoro".

Isso indica claramente que apesar de o "ficar" ser mais conhecido e lembrado quando se indaga sobre os relacionamentos existentes, não é citado como o relacionamento preferido, aquele que o adolescente imagina como ideal ou que gostaria de viver ao longo da vida. No caso das meninas, essa tendência a não incorporar o "ficar" como um ideal de vida é ainda mais acentuada. O que essa aparente discrepância significa? Ganha força a hipótese de que o "ficar" é um modo de explorar e experimentar sentimentos, parceiros e situações para a realização de escolhas e para a tomada de decisões mais realistas. De fato, é perfeitamente compreensível que os adolescentes se lancem a experiências variadas e breves com o intuito de conhecer melhor o parceiro. Nesse sentido não haveria tanta diferença entre o "ficar" e a paquera, embora essa seja tida como uma primeira aproximação que se inicia com olhares e avança para uma conversa mais reservada e íntima, enquanto o "ficar" envolve algum tipo de contato físico como carícias e beijos, podendo culminar numa relação sexual.

Ainda de acordo com a pesquisa citada, o "ficar" foi definido pelos adolescentes, tanto meninos como meninas, como um primeiro contato que poderia levar a um namoro, reafirmando a tese da busca de um maior conhecimento sobre o parceiro. Porém, foi caracterizado também como um passatempo e uma simples diversão. A "ausência de compromisso" foi, de longe, a característica mais citada.

A busca de um prazer imediato e fortuito foi expressa da seguinte forma:

“[...] Ficar: é só ficar um ou dois dias, não é gostar da pessoa, é só para se divertir" (15 anos, sexo fem.).

"ficar: quando conhecemos alguém interessante, ficamos apenas por algumas horas para curtir aquele momento[...]" $(16$ anos, sexo fem.)

"[...] Ficar é ter desejo de beijar, abraçar e até mesmo transar com uma pessoa. A pessoa realiza esse desejo e fica com a pessoa mais ou menos 2 ou 3 dias e depois se esquece dela. Namorar: é um relacionamento mais sério onde você vai conhecer mais a fundo a pessoa" (17 anos, sexo fem.) (MARIANO, 2001, p. 78-79).

Esses depoimentos assinalam que o "ficar" pode ter o sentido de um relacionamento passageiro e fugaz no qual os parceiros buscam "curtir;" o momento que estão juntos sem visarem algo além daquele encontro, mesmo que se prolon- 
gue por alguns dias. O envolvimento ou um "sentimento" mais forte não é condição para o "ficar" tal como diz o sujeito do primeiro depoimento.

Portanto, embora ele possa ser visto e vivido como um primeiro contato com um parceiro tendo em vista um possível namoro, nem sempre aparece revestido desse objetivo. Aliás, em sua versão mais radical sequer possui algum objetivo entendido como algo que é lançado para além do momento do encontro. É um "estar junto" que se esgota em si mesmo sem produzir outros desdobramentos. Nem mesmo a repetição da experiência é buscada novamente. Portanto, se o "ficar" pode expressar uma paquera mais ousada, nesse sentido reeditando formas de aproximação e contato bastante antigas, expressa também um contato íntimo e erótico imediato sem prolongar-se no tempo ou no espaço, não se prestando a produzir novos encontros, produções do casal em outras esferas da vida ou fortalecimentos de vínculos.

Além de se constituir como um desdobramento da paquera tradicional, visualizamos também uma outra gênese do "ficar": os relacionamentos que os adolescentes, no passado, estabeleciam com prostitutas ou "garotas que mantinham relações sexuais". Especialmente nas pequenas cidades, a iniciação sexual dos meninos ocorria com prostitutas mais velhas ou meninas que, mesmo não sendo prostitutas, cediam aos avanços sexuais dos rapazes. Essas meninas eram, obviamente, bastante discriminadas, consideradas pervertidas, "vagabundas" e depravadas, principalmente quando eram pobres. Eram procuradas pelos rapazes apenas para encontros sexuais às escondidas. Jamais algum deles se permitia ser visto em público na companhia de uma delas. Quando uma nova menina desse tipo era descoberta virava notícia na cidade e a rapaziada enfileirava-se nas cantadas. Algumas situações criadas em torno dessa prática acabava se convertendo em folclore da cidade sobre as aventuras sexuais dos rapazes. Às vezes acontecia uma gravidez ou a denúncia de abuso e um processo acabava sendo encaminhado ao Fórum da comarca. Ao longo das audiências, como eram muitos os acusados, formavam-se filas de adolescentes para depor. A notícia corria de boca em boca na cidade provocando piadas, chacotas, gracejos e os rapazes acusados exibiam um sentimento misto de constrangimento com orgulho por ter provado sua virilidade.

A menina, evidentemente, acabava sofrendo a brutal humilhação de ser exposta perante toda a cidade como devassa e prostituta. Ali acabava sua chance de vir a ter um namorado ou uma vida afetiva que não significasse ser explorada sexualmente pelos rapazes.

Essa situação revela muito bem a condição de dominação e submissão que historicamente se abate sobre a mulher, tornando-a vítima da crueldade, abuso, sadismo e exploração perpetrada através das relações de gênero. É claro que tal vitimização ocorria de forma mais brutal com as meninas pobres - tornadas objeto sexual dos rapazes de famílias ricas - porém, também atingia meninas de famílias abastadas que, mesmo não sendo expostas à execração pública, como as meninas pobres, sofriam algum tipo de preconceito. Tinham mais dificuldade para encontrar namorados "firmes" e também acabavam sendo vistas como boas parceiras para uma noitada, mas não para um casamento. Entravam, de qualquer maneira, 
na categoria das meninas que "não eram mais virgens" e que, portanto, jamais seriam cogitadas para um possível casamento.

As expressões "namoro firme" ou "namoro sério", são bastante antigas e ainda hoje são utilizadas para designar relacionamentos com um maior grau de compromisso e longevidade. O namoro que, em épocas anteriores, não era "firme" ou "sério" aproximava-se bastante do "ficar" (diversão) da atualidade, embora fosse mais exigente quanto à fidelidade e à durabilidade. Mas também soava como um contato preliminar para um melhor conhecimento do outro, dos próprios sentimentos ou, simplesmente, como se dizia, um namoro apenas para "passar o tempo".

O caso da exploração sexual das meninas pelos meninos não deixa de ter alguma afinidade com o "ficar". Representava, embora de forma perversa, um encontro erótico fortuito, passageiro que se limitava apenas à relação sexual. A grande diferença é que o ficar é aceito socialmente, e até valorizado entre os adolescentes, não acarretando, portanto, a vergonha, a busca do anonimato e a discriminação social, pelo menos no grau em que ocorria com as "meninas desonradas" de outrora.

Porém, de qualquer maneira, é necessário ter alguma cautela quanto à aceitabilidade do "ficar" hoje. É possível observar entre alguns adolescentes, notadamente entre as meninas, para variar, a existência de um tom de recriminação em relação àqueles que "ficam" com bastante freqüência, principalmente se esse "ficar" incluir relações sexuais. De forma parecida com a da época descrita anteriormente, essas meninas passam a ser vistas como "galinhas", "não-sérias" e "não-confiáveis", passíveis de rejeição tanto da parte dos meninos como das meninas.

Essa provável ancestralidade do "ficar" atualiza os mesmos conflitos e problemas vividos pelos jovens em relação à sexualidade e a relacionamentos amorosos. Por um lado, há uma busca de liberdade, prazer, felicidade e, por outro, dilemas, freios e contradições insuperáveis. É bom "ficar" mas a falta de uma perspectiva de futuro produz uma sensação de desamparo e insegurança; é bom namorar e casar, mas a vida fica muito limitada e pesada pelos compromissos assumidos, encargos domésticos e dificuldades na convivência diária - o preço a pagar pela segurança e pela confiança.

Os dilemas dos jovens de outras épocas também percorriam contradições equivalentes: namorar e casar com as moças recatadas e insossas ou lançar-se à libertinagem com as depravadas e prostitutas. Antes esses dilemas encontravam saída na célebre cisão entre a "vida conjugal" (com a esposa) e a "vida libertina" (nas zonas de prostituição). Hoje, como a contradição não é moral (embate entre um desejo e sua interdição), mas sim "existencial", ou seja, trata-se de realizar uma opção que exige contrapartida e não há opção que seja completamente satisfatória, o dilema parece ser mais radical por não apresentar uma solução possível, mesmo que defensiva. 
Também como antes, é sobre a mulher que recai o ônus maior da convivência com os dilemas e angústias gerados em torno dos relacionamentos amorosos e da sexualidade. É a vítima maior de preconceitos ainda existentes quanto à forma ou intensidade de certos relacionamentos e é sobre ela que também recai, com mais intensidade, o sofrimento produzido pela sensação de desamparo, insegurança e desconfiança relacionados aos modelos contemporâneos de relacionamento afetivo.

$\mathrm{O}$ adolescente vive os dilemas e conflitos de um momento marcado pela transição do paradigma do "amor romântico" para o do "amor confluente" de acordo com as categorias de relacionamento amoroso propostas por Giddens (1993). Segundo esse autor, o amor romântico, típico dos séculos XVIII e XIX, cede lugar hoje ao amor confluente, significando isso que aquele amor jurado à eternidade, estruturador de relacionamentos indissolúveis, fincado na renúncia e na abnegação, suporte do espaço da intimidade na família, está sendo substituído por um amor que exige correspondência, confluência de interesses e desejos e que institui relacionamentos contingentes, negociados e duráveis, não até a morte, mas sim até a finitude dos interesses de uma ou de ambas as partes.

O amor confluente é expressão dos avanços das conquistas de maior igualdade nas relações de gênero, da liberdade quanto às escolhas de parceiros e interrupções de relacionamentos conjugais e é também expressão da maior mobilidade espaço-temporal do sujeito na contemporaneidade.

Basicamente, o adolescente vive a tensão gerada por modelos de amor e relacionamentos antigos e modelos gerados pelas forças psicossociais da atualidade. Se por um lado é atraente o ideário do amor romântico, pela promessa de segurança, confiabilidade, fidelidade, durabilidade e outras vantagens, por outro, também é fascinante a promessa da maior independência, autonomia, realização, diversidade e outras coisas com as quais o amor confluente acena.

Além disso, não se trata apenas de escolher entre duas alternativas, mas sim ter de assimilar, no plano afetivo, aquilo que viceja em todos os âmbitos da sociedade contemporânea. Por isso mesmo, o "ficar" não é apenas um avanço de antigas formas de paquera. É um relacionamento que tende a se tornar hegemônico ou paradigmático das formas de relacionamento na contemporaneidade, ou seja, ele expressa fundamentalmente a compressão do tempo e do espaço na atualidade.

\section{Conclusão}

O ficar não é um modismo ou um fenômeno superficial e isolado, mas conecta-se com outras subjetivações produzidas na sociedade contemporânea. Aliás, tal modalidade pode ser tomada como expressão dos novos paradigmas de relacionamento emergentes nesse tempo. Obedece à mesma lógica que também governa relacionamentos de diferentes espécies e naturezas. A abreviação do tempo e o caráter efêmero e provisório do "ficar" estão presentes em vários outros cenários da contemporaneidade. Não são apenas os jovens que estão vivendo a condição de encurtamento e abreviação de seus relacionamentos amorosos, mas também os 
trabalhadores. Como ilustração podemos citar a abreviação dos vínculos empregatícios e a rarefação dos relacionamentos outrora sólidos e duradouros, tais como os de vizinhança, amizade e os familiares.

Vive-se hoje uma condição de aceleração do tempo, alargamento do espaço e de movimentação humana sem precedentes, impeditiva de vinculações psicossociais estáveis e prolongadas. Trata-se de um sujeito errante, condicionado a conviver com a incerteza, o risco, a insegurança a provisoriedade em todos os planos da vida: do amor ao trabalho. As forças de dispersão, contrapostas às antigas forças de agregação e de confinamento, condenam o sujeito a conviver com a solidão ou a estabelecer relacionamentos mínimos e transitórios. A descartabilidade associada à pressão pelo consumismo - outra figura forte da contemporaneidade também potencializa consideravelmente a brevidade dos vínculos e contatos com todo tipo de objetos do desejo.

O "ficar", portanto, inscreve-se nesse paradigma da contemporaneidade que privilegia a compressão do tempo, a expansão das fronteiras geográficas, econômicas, políticas e psicossociais, o nomadismo, o desamparo, o desprendimento, $\mathrm{o}$ isolamento, o individualismo, o hedonismo, o narcisismo, o desapego, o jogo, o acaso e tantas outras condições produtoras de uma subjetividade oscilante e intermitente.

\section{REFERÊNCIAS}

AZEVEDO, F. A cultura brasileira. Brasília, DF: Ed. Da Universidade de Brasília, 1963.

AUGÉ, M. Não lugares: introdução a uma antropologia da super modernidade. Campinas, SP: Papirus, 1994.

BAUMAN, Z. Mal-estar da pós-modernidade. Rio de Janeiro: Zahar, 1998.

BERMAN, M. Tudo que é sólido desmancha no ar: a aventura da modernidade. São Paulo: Companhia da Letras, 1986.

CALligARIS, C. Hello Brasil. Porto Alegre: Artes Médicas, 1992.

FREYRE, G. Casa grande e senzala: formação da família brasileira sob o regime de economia patriarcal. Rio de Janeiro: Schmidt, 1936.

. Ordem e progresso. Rio de Janeiro: Record, 2000.

GIDDENS, A. As consequiências da modernidade. São Paulo: Unesp, 1991.

A transformação da Intimidade: sexualidade, amor e erotismo nas sociedades modernas. São Paulo: Unesp, 1993.

HARVEY, D. Condição Pós-Moderna. São Paulo: Loyola, 1998. 
JUSTO, J. S. Criatividade no mundo contemporâneo. In: Criatividade: Psicologia, Educação e Conhecimento do Novo. São Paulo: Moderna.

MAFFESOLI, Sobre o Nomadismo: vagabundagens pós-modernas. São Paulo: Record, 2001.

MARIANO, C. L. S. Um estudo sobre os relacionamentos amorosos na adolescência. Dissertação (mestrado)-Universidade Estadual de São Paulo, São Paulo, 2001.

ROLNIK, S. Toxicômanos de Identidade: subjetividade em tempo de globalização. In: LINS, D. (Org.). Cultura e subjetividade: saberes nômades. Campinas, SP: Papirus, 1997.

SANTAELLA, L. O que é Semiótica, 12. ed. São Paulo: Brasiliense, 1996.

WEINGÄRTNER, C. L. et al. O ficar e o namorar vistos pelos adolescentes. Psicologia: Reflexão e Crítica, Porto Alegre, v. 8, n. 2, p. 181-203, 1995.

Recebido em: outubro /2004 Aceito em: fevereiro / 2005 
